\title{
Dietary Flavonoid Hyperoside Induces Apoptosis of Activated Human LX-2 Hepatic Stellate Cell by Suppressing Canonical NF- $\kappa$ B Signaling
}

\author{
Liwen Wang, ${ }^{1,2}$ Zhiwei Yue, ${ }^{3}$ Mengzheng Guo, ${ }^{2}$ Lianying Fang, ${ }^{2}$ Liang Bai, ${ }^{1}$ Xinyu Li, ${ }^{1}$ \\ Yongqing Tao, ${ }^{1}$ Suying Wang, ${ }^{1}$ Qiang Liu, ${ }^{2}$ Dexian Zhi, ${ }^{1}$ and Hui Zhao' \\ ${ }^{1}$ Tianjin Key Laboratory of Food and Biotechnology, School of Biotechnology and Food Science, Tianjin University of Commerce, \\ Tianjin 300134, China \\ ${ }^{2}$ Tianjin Key Laboratory of Radiation Medicine and Molecular Nuclear Medicine, Institute of Radiation Medicine, \\ Chinese Academy of Medical Sciences and Peking Union Medical College, Tianjin 300192, China \\ ${ }^{3}$ Department of Hematology and Tangshan Key Laboratory, Translational Medical Center, \\ North China University of Science and Technology, Tangshan, Hebei 063000, China
}

Correspondence should be addressed to Qiang Liu; liuqiang@irm-cams.ac.cn, Dexian Zhi; zdx@tjcu.edu.cn, and Hui Zhao; zhaohui@tjcu.edu.cn

Received 4 January 2016; Accepted 1 March 2016

Academic Editor: Yiannis Kourkoutas

Copyright (C) 2016 Liwen Wang et al. This is an open access article distributed under the Creative Commons Attribution License, which permits unrestricted use, distribution, and reproduction in any medium, provided the original work is properly cited.

\begin{abstract}
Hyperoside, an active compound found in plants of the genera Hypericum and Crataegus, is reported to exhibit antioxidant, anticancer, and anti-inflammatory activities. Induction of hepatic stellate cell (HSC) apoptosis is recognized as a promising strategy for attenuation of hepatic fibrosis. In this study, we investigated whether hyperoside treatment can exert antifibrotic effects in human LX-2 hepatic stellate cells. We found that hyperoside induced apoptosis in LX-2 cells and decreased levels of $\alpha$-smooth muscle actin ( $\alpha$-SMA), type I collagen, and intracellular reactive oxygen species (ROS). Remarkably, hyperoside also inhibited the DNA-binding activity of the transcription factor NF- $\kappa \mathrm{B}$ and altered expression levels of NF- $\kappa \mathrm{B}$-regulated genes related to apoptosis, including proapoptotic genes $B c l-X s, D R 4$, Fas, and FasL and anti-apoptotic genes $A 20, c-I A P 1, B c l-X_{L}$, and RIP1. Our results suggest that hyperoside may have potential as a therapeutic agent for the treatment of liver fibrosis.
\end{abstract}

\section{Introduction}

Liver fibrosis is a major cause of morbidity and mortality worldwide due to chronic viral hepatitis and, more recently, from fatty liver disease associated with obesity [1]. Hepatic fibrosis is largely asymptomatic. However, progressive fibrosis resulting in cirrhosis can cause distortion of the liver parenchyma and vascular architecture [2], of which major clinical consequences are impaired liver function, an increased portal hypertension, and the development of hepatocellular carcinoma [3]. An epidemiological analysis has identified liver cirrhosis as a leading cause of diseaserelated death worldwide [4].

Liver fibrosis is a reversible, progressive pathological process characterized by excess accumulation of extracellular matrix (ECM) proteins. Hepatic stellate cells (HSCs) are quiescent, nonproliferative, vitamin-A storing cells; they are localized to the space of Disse and function as the principal storage sites of retinoids in normal liver. HSCs are the principal cell type involved in liver fibrogenesis, and the survival of activated HSCs is the hallmark feature of liver fibrosis. Upon activation, HSCs proliferate and undergo transdifferentiation from quiescent cells to activated myofibroblast-like cells secreting excess ECM proteins [5]. Antifibrotic drug research focuses on the inhibition of HSC activation or proliferation and the promotion of apoptosis in activated HSCs $[6,7]$. Given the current lack of successful treatment options for liver fibrosis, new strategies for slowing this process are urgently needed. 
In addition to the activation of fibroblasts and immune cells, fibrosis-inducing events also cause release of profibrotic metabolites such as reactive oxygen species (ROS). ROS are critical intermediates in both liver physiology and pathology. Recent research indicates that oxidative stress and the antioxidant system may also be critical for the development and persistence of fibrosis [8]. In addition to ROS, the transcription factor nuclear factor-kappa $\mathrm{B}(\mathrm{NF}-\kappa \mathrm{B})$ is also essential for liver cell survival and liver homeostasis [9]. The regulation of cell death, inflammation, and wound healing by NF- $\kappa$ B not only emphasizes the role of this transcription factor in the progression of liver diseases, but also highlights the mechanistic links between liver injury, inflammation, fibrosis, and hepatocellular carcinoma [10]. Several studies have indicated that NF- $\kappa \mathrm{B}$ inhibition is a potent mechanism for the induction of HSC apoptosis $[11,12]$. Hence, when NF$\kappa \mathrm{B}$ activation is prevented or inhibited, apoptosis of activated HSCs is enhanced.

Natural products have recently attracted much attention in drug research because they have frequently served as major sources of chemical diversity for novel biomedical agents and pharmaceutical discovery. Flavonoids are plant polyphenols found in vegetables, fruits, and plant-based beverages and are well known for their physiological antipyretic, analgesic, and anti-inflammatory activities [13]. Hyperoside (also called quercetin 3-O-b-d-galactoside; Figure 1(a)), a major pharmacologically active component from the genera Hypericum and Crataegus [14], has been demonstrated to possess numerous biological functions, including cardioprotective [15], antiredox [16], and anti-inflammatory activities [17]. Hyperoside also displays antiviral activity against hepatitis B in HepG2 cells transfected with hepatitis B viral genome, via the suppression of hepatitis B antigen secretion [18]. However, little research has been conducted on the potential roles and mechanisms of hyperoside in the treatment of liver fibrosis. In the present study, we utilized the human HSC line LX2, which preserves key features of primary HSCs critical for liver fibrosis research [19], to investigate the molecular mechanisms of the proapoptotic effects of hyperoside.

\section{Materials and Methods}

2.1. Cell Culture. LX-2 cells were gifted by Dr. Zhigang Bai, Liver Research Center, Beijing Friendship Hospital, Beijing, China. Cells were cultured in RPMI-1640 medium (Thermo Fisher, Beijing, China) containing 10\% fetal bovine serum at $37^{\circ} \mathrm{C}$ in a $5 \% \mathrm{CO}_{2}$ incubator. Hyperoside (Biopurify, Chengdu, China) was dissolved in dimethyl sulfoxide (DMSO, Solarbio, Beijing, China) and added at the concentrations indicated.

2.2. Cell Viability Assay. 3-(4,5-Dimethyl-2-thiazolyl)-2,5diphenyl-2H-tetrazolium bromide (MTT, Sigma, M5655, USA) was used as an indicator of cell viability. Cells were grown in 96-well plates at a density of $5 \times 10^{3}$ cells/well. After $24 \mathrm{~h}$, the cells were washed with fresh medium, followed by treatment with hyperoside. After a $24 \mathrm{~h}$ or $48 \mathrm{~h}$ incubation period, the cells were washed, and $100 \mu \mathrm{L}$ of MTT $(1 \mathrm{mg} / \mathrm{mL})$ was added, followed by incubation for $4 \mathrm{~h}$. Finally, DMSO
$(150 \mu \mathrm{L})$ was added in order to solubilize the formazan salt formed, and the amount of formazan salt was determined by measuring the $\mathrm{OD}$ at $540 \mathrm{~nm}$ using a microplate reader (Synergy HT; BioTek Instruments).

2.3. Apoptosis Quantification. Detection of apoptosis was performed with an Annexin V-FITC/PI kit (BD Biosciences, New Jersey, USA) according to the manufacturer's instructions. Cells were seeded in 6 -well plate $\left(1 \times 10^{6}\right.$ cells/well $)$ and treated with different concentrations $(0.5 \mu \mathrm{M}, 1.0 \mu \mathrm{M}$, or $2.0 \mu \mathrm{M})$ of hyperoside at $37^{\circ} \mathrm{C}$ for $24 \mathrm{~h}$ or $48 \mathrm{~h}$. Cells were harvested, washed twice with ice-cold PBS, and resuspended in $1 \mathrm{~mL}$ binding buffer. Resuspended cells $(100 \mu \mathrm{L})$ were transferred to a $1.5 \mathrm{~mL}$ EP tube and $5 \mu \mathrm{L}$ Annexin V-FITC plus $5 \mu \mathrm{L}$ PI was added. The tube was gently vortexed and incubated for $15 \mathrm{~min}$ at room temperature in the dark. Binding buffer $(400 \mu \mathrm{L})$ was then added and the cells were analyzed immediately by flow cytometry. Percentage of Annexin V-FITC ${ }^{+}$ cells was represented as apoptosis rate [20].

2.4. Western Blotting Analysis. Protein was extracted from LX-2 cells prepared with ice-cold lysis buffer (P1016, Solarbio Science and Technology, Beijing, China). Protein concentration in cell lysates was determined with a BCA protein kit (Beyotime, Shanghai, China). Samples containing equal amounts of protein $(20 \mathrm{~g})$ were mixed with loading buffer containing 5\% 2-mercaptoethanol, heated for $5 \mathrm{~min}$ at $95^{\circ} \mathrm{C}$, loaded onto a $10 \%$ SDS-PAGE gel, and then transferred to polyvinylidene difluoride (PVDF) membranes. After blocking with $5 \%$ milk and $0.1 \%$ Tween 20 in Tris-buffered saline (TBS), membranes were incubated overnight at $4^{\circ} \mathrm{C}$ with primary antibody. Antibodies against $\alpha$-SMA (BM0002) and collagen I (BA0325) were purchased from Boster (Wuhan, China); $\beta$-tubulin (CW0098) was purchased from CWBIO (Beijing, China). Membranes were then incubated with the appropriate horseradish peroxide conjugated secondary antibody at room temperature. Protein bands were detected using ECL (WBKLS0100, Millipore, Billerica, MA, USA), according to the manufacturer's protocols. Experiments were repeated three times.

2.5. Intracellular Reactive Oxygen Species Assay. The production of intracellular reactive oxygen species was measured by DCFH oxidation. The DCF-DA reagent passively enters cells, where it is deacetylated by esterases into nonfluorescent DCFH. Inside the cell, DCFH reacts with ROS to form DCF, a fluorescent product. For this assay, $10 \mathrm{mM}$ DCF-DA (S0033, Beyotime, Jiangsu, China) was dissolved in methanol and diluted 1000-fold in RPMI-1640 medium to give a final concentration of $10 \mu \mathrm{M}$ DCF-DA. Hyperoside treated LX2-enriched cultures seeded $\left(5 \times 10^{4} /\right.$ well $)$ in 96 -well plates were then incubated with DCFH-DA for 20 minutes at $37^{\circ} \mathrm{C}$. Immediately after incubation, DCF fluorescence was read at $485 \mathrm{~nm}$ excitation and $530 \mathrm{~nm}$ emission by flow cytometry.

2.6. $N F-\kappa B$ DNA-Binding Activity. The Trans-AM NF- $\kappa \mathrm{B}$ p 65 Transcription Factor Assay kit (Active Motif North America, Carlsbad, CA) was used to quantify the DNA-binding activity 
<smiles>O=c1c(O[C@@H]2O[C@H](CO)[C@@H](O)[C@H](O)[C@H]2O)c(-c2ccc(O)c(O)c2)oc2cc(O)cc(O)c12</smiles>

Hyperoside

(a)

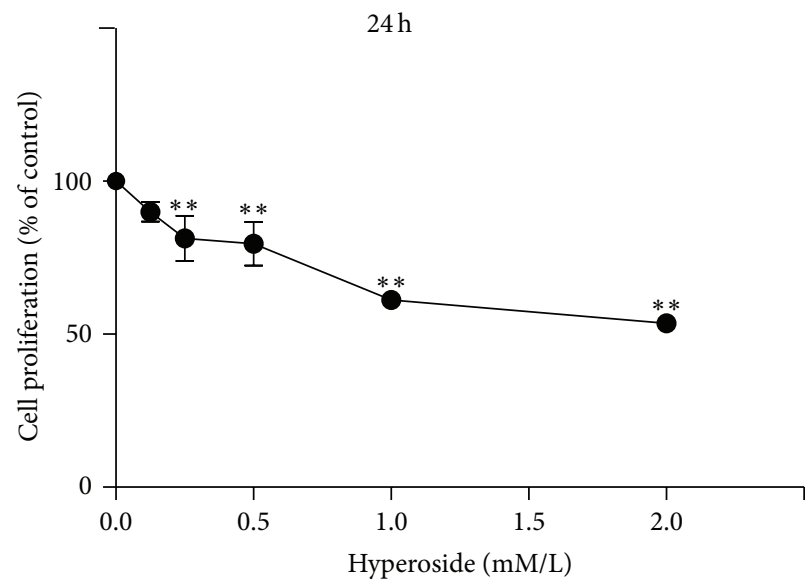

(b)

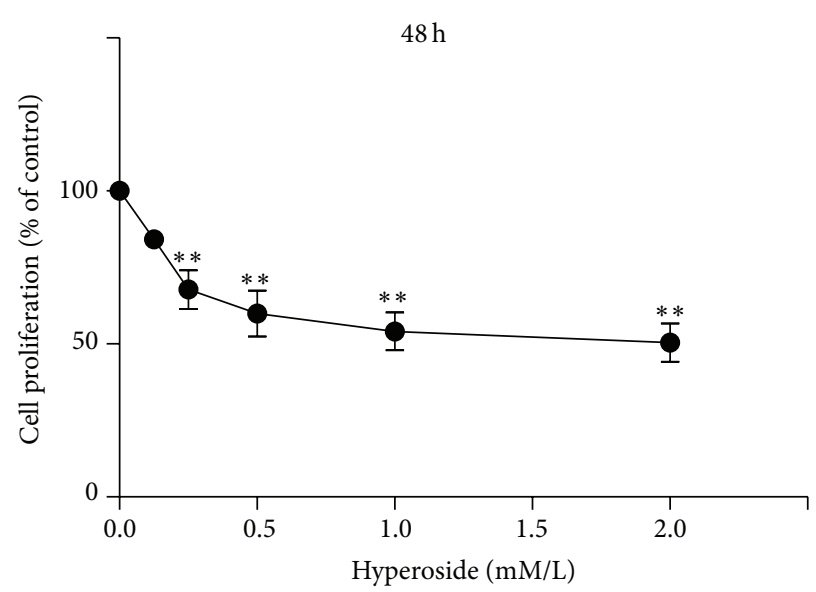

(c)

Figure 1: Structure of hyperoside and its inhibitory proliferation effect on LX-2 cells. (a) Chemical structure of hyperoside. (b) Effect of hyperoside on the growth of LX-2 cell lines for $24 \mathrm{~h}$. (c) Effect of hyperoside on the growth of LX-2 cell lines for $48 \mathrm{~h}$. Cell proliferation was analyzed using MTT assay. Cells were treated with different concentration of hyperoside $(0,0.125,0.25,0.5,1.0$, and $2.0 \mathrm{mM} / \mathrm{L})$. Results represent the mean \pm SEM from three independent experiments $\left({ }^{* *}\right.$ means compared with the control group, $\left.P<0.001\right)$.

of NF- $\kappa$ B in LX-2 cells, according to the instructions of the manufacturer. Briefly, nuclear extracts were prepared with NE-PER nuclear and cytoplasmic extraction reagents (Pierce Biotechnology Rockford, IL). Protein content in the two fractions was quantitated using a Bradford assay. Nuclear extracts were incubated in 96-well plates coated with immobilized oligonucleotide $\left(5^{\prime}\right.$-AGTTGAGGGGACTTTCCCAGGC- $\left.{ }^{\prime}\right)$ containing a consensus $\left(5^{\prime}\right.$-GGGACTTTCC- $\left.3^{\prime}\right)$ binding site for the p65 subunit of NF- $\kappa$ B. NF- $\kappa$ B binding to the target oligonucleotide was detected by incubation with primary antisera specific for the activated form of p65. The ELISA assay was developed with anti-IgG horseradish peroxidase conjugate and developing solution provided with the kit. Optical density (OD) was determined at $450 \mathrm{~nm}$ with a reference wavelength of $655 \mathrm{~nm}$. Background binding was subtracted from the value obtained for binding to the consensus DNA sequence.

2.7. Quantitative RT-PCR. Total RNA was extracted from LX2 cells using TRIzol Reagent (Invitrogen, Carlsbad, CA). A
$10 \mu \mathrm{g}$ aliquot of each RNA sample was reverse transcribed into cDNA using oligo-dT random primers and reverse transcriptase. Quantitative real-time PCR was performed using SYBR Premix Ex Taq ${ }^{\mathrm{TM}}$ II (Takara, Japan). The primers used are shown in Table 1. 18s was used as a housekeeping gene.

2.8. Statistical Analysis. Data are expressed as mean \pm SEM, representing at least three independent experiments. Statistical analysis was conducted using SPSS software (SPSS version 14.0, SPSS Science, Chicago, IL, USA). One-way analysis of variance (ANOVA) was followed by least significant difference (LSD) test. A $P$ value of less than $0.05(P<0.05)$ was considered to indicate statistical significance.

\section{Results}

3.1. Hyperoside Inhibits LX-2 Proliferation. The chemical structure of hyperoside is shown in Figure 1(a). The fibrogenic activities of HSCs are based on their activation and 
TABLE 1: Primers of quantitative real-time PCR.

\begin{tabular}{|c|c|c|c|}
\hline \multirow{2}{*}{ Primers } & \multicolumn{2}{|c|}{ Sequence } & \multirow{2}{*}{ Annealing temperature $\left({ }^{\circ} \mathrm{C}\right)$} \\
\hline & Forward (from $5^{\prime}$ to $\left.3^{\prime}\right)$ & Reverse (from $5^{\prime}$ to $3^{\prime}$ ) & \\
\hline $18 \mathrm{~s}$ & CAGCCACCCGAGATTGAGCA & TAGTAGCGACGGGCGGTGTG & 60 \\
\hline$\alpha$-SMA & AGGTAACGAGTCAGAGCTTTGGC & СTCTCTGTCCACCTTCCAGCAG & 60 \\
\hline Collagen I & GAGCGGAGAGTACTGGATCG & GTTCGGGCTGATGTACCAGT & 60 \\
\hline $\mathrm{A} 20$ & GTCCGGAAGCTTGTGGCGCT & CCAAGTCTGTGTCCTGAACGCCC & 55 \\
\hline Bcl-Xs & GCAGTAAAGCAAGCGCTGAG & GTTCCACAAAAGTATCCTGTTCAAAG & 60 \\
\hline DR4 & CTGAGCAACGCAGACGCGCTGTCCAC & ACAGCATCAGAGTCTCAGTGGGGTCAGC & 60 \\
\hline Fas & ATTCTGCCATAAGCCCTGTC & TTGGTGTTGCTGGTGAGTGT & 55 \\
\hline FasL & GTTCTGGTTGCCTTGGTAGG & TGTGCATCTGGCTGGTAGAC & 55 \\
\hline c-IAP1 & TTGTCAACTTCAGATACCACTGGAG & CAAGGCAGATTTAACCACAGGTG & 60 \\
\hline $\mathrm{Bcl}-\mathrm{X}_{\mathrm{L}}$ & AGTTCCCTTGGCCTCAGAAT & AGGGTTGCACCAATCAGGTA & 55 \\
\hline Rip1 & GTCAAATTCAGCCACAGAACAGCC & CССTTTAGССТTСССТСАТСACС & 55 \\
\hline
\end{tabular}

proliferation. To explore the potential antifibrotic effects of hyperoside, the viability of LX-2 cells following hyperoside treatment was determined by MTT assay. As shown in Figures 1(b) and 1(c), hyperoside treatment for both $24 \mathrm{~h}$ and $48 \mathrm{~h}$ significantly reduced LX-2 cell viability in a dosedependent manner. The $50 \%$ inhibitory concentration $\left(\mathrm{IC}_{50}\right)$ values for hyperoside were determined as $1.16 \mathrm{mM}$ for $24 \mathrm{~h}$ treatment and $0.78 \mathrm{mM}$ for $48 \mathrm{~h}$ treatment.

3.2. Hyperoside Promotes Apoptosis in LX-2 Cells. To determine whether the decrease in cell viability we observed in hyperoside treated LX-2 cells was attributable to the induction of apoptosis, we examined the rate of LX-2 apoptosis using Annexin V-FITC/PI labeling. Figure 2 showed that hyperoside treatment induced apoptosis in a concentrationdependent manner in LX-2 cells. The rate of apoptosis did not increase significantly in cells treated for only $24 \mathrm{~h}$, while $48 \mathrm{~h}$ of hyperoside treatment significantly increased the rate of apoptosis in LX-2 cells. After 48 h of hyperoside treatment, the curvilinear response had an inflection point at the $0.5 \mathrm{mM}$ dose, at which apoptosis rate was significantly increased. Because of these findings, we used hyperoside at a concentration of $1 \mathrm{mM}$ in subsequent experiments involving the LX-2 cell line. These results indicate that growth inhibition of LX-2 cells by hyperoside is associated with apoptosis.

3.3. Hyperoside Downregulates Endogenous $\alpha$-SMA and ECM Protein Levels in LX-2 Cells. The major phenotypical transformation that follows HSC activation is the transdifferentiation into $\alpha$-smooth muscle actin- ( $\alpha$-SMA-) positive myofibroblasts that have increased cell proliferation and produce large amounts of ECM proteins such as collagen I [5]. The effect of hyperoside on expression of the HSC activation markers $\alpha$-SMA and type I collagen was evaluated by western blotting. LX-2 cells were exposed to hyperoside for $48 \mathrm{~h}$, and total protein was isolated for subsequent analysis. As depicted in Figure 3(a), secretion of $\alpha$-SMA was inhibited by hyperoside, but the effect was not statistically significant until treated with $2.0 \mu \mathrm{M}$ hyperoside. Treatment with $0.5 \mu \mathrm{M}$ hyperoside slightly suppressed the expression of collagen I levels, and the protein levels markedly decreased when the hyperoside is $1.0 \mu \mathrm{M}$. As depicted in Figure 3(a), treatment with $0.5 \mu \mathrm{M}$ or $1.0 \mu \mathrm{M}$ hyperoside slightly decreased $\alpha$-SMA and collagen I levels. Treatment with $2.0 \mu \mathrm{M}$ hyperoside markedly decreased $\alpha$-SMA and collagen I protein levels.

Next, we quantified mRNA levels of $\alpha$-SMA and collagen I using quantitative RT-PCR. As illustrated in Figure 3(b), $\alpha$-SMA mRNA levels were significantly decreased in LX-2 cells treated with $2.0 \mu \mathrm{M}$ hyperoside. A significant decrease in collagen I gene expression was also observed. These results are consistent with the decreased protein levels shown in Figure 3(a).

3.4. Hyperoside Attenuates Intracellular ROS Production in LX-2 Cells. Flavonoids are broadly recognized for their natural antioxidant properties [21], while ROS have been associated with fibrosis in several organs, especially in the liver $[22,23]$. When we treated LX-2 cells with hyperoside at multiple concentrations and measured intracellular ROS levels by DCF-DA fluorescence, we found that hyperoside drastically reduced intracellular ROS production in activated liver fibrosis cells (Figure 4(a)). Quantitative evaluation of DCF fluorescence (Figure 4(b)) found that this inhibitory effect on intracellular ROS production was reduced by approximately $60 \%$ compared to control levels. We are the first to report that hyperoside attenuates intracellular ROS production in LX-2 cells.

3.5. Hyperoside Blocks NF- $\kappa B$ Activation in LX-2 Cells. To evaluate the NF- $\kappa \mathrm{B}$-inhibiting effects of hyperoside, nuclear extracts were prepared from pretreated LX-2 cells and the subcellular localization of the NF- $\kappa$ B RelA/p65 DNA-binding complex was examined. As shown in Figure 5(a), TNF- $\alpha$ was effective in inducing NF- $\kappa$ B DNA-binding activity. Nuclear extracts from control LX-2 cells demonstrated high levels of NF- $\kappa$ B DNA-binding activity, which was reduced by nearly $50 \%$ after hyperoside treatment when compared to the TNF$\alpha$ induced group. This finding demonstrates that hyperoside can markedly attenuate TNF- $\alpha$ induced NF- $\kappa$ B activation in LX-2 cells. 


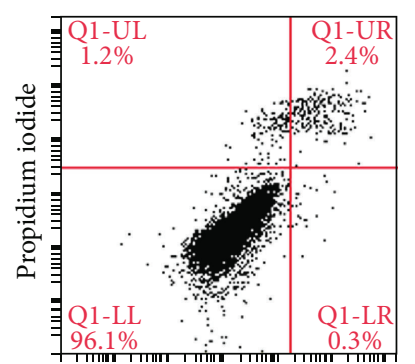

Hyperoside $0 \mathrm{mM} / \mathrm{L}$

Annexin- $\mathrm{V}$

$24 \mathrm{~h}$

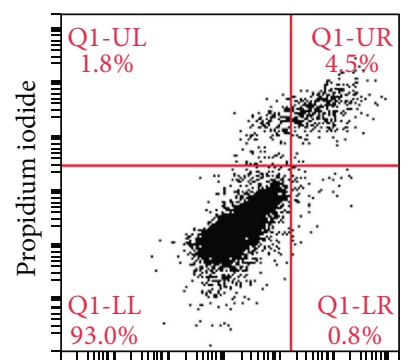

Hyperoside $1 \mathrm{mM} / \mathrm{L}$ Annexin-V $24 \mathrm{~h}$

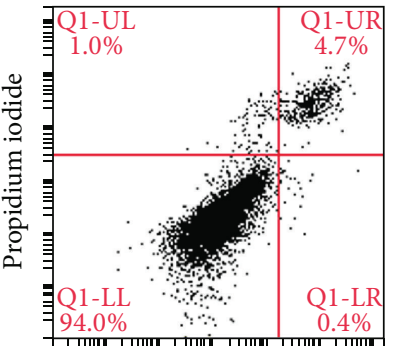

Hyperoside $0.5 \mathrm{mM} / \mathrm{L}$

Annexin- $\mathrm{V}$

$24 \mathrm{~h}$

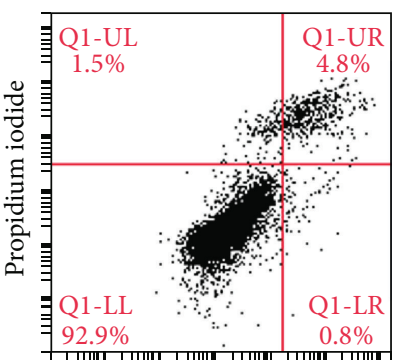

Hyperoside $2 \mathrm{mM} / \mathrm{L}$

Annexin-V

$24 \mathrm{~h}$

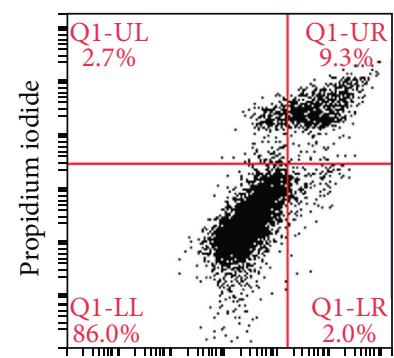

Hyperoside $0 \mathrm{mM} / \mathrm{L}$ Annexin-V

$48 \mathrm{~h}$

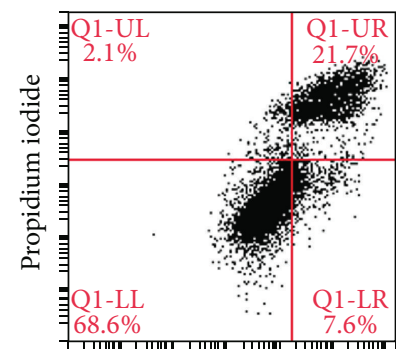

Hyperoside $1 \mathrm{mM} / \mathrm{L}$

Annexin- $\mathrm{V}$

$48 \mathrm{~h}$

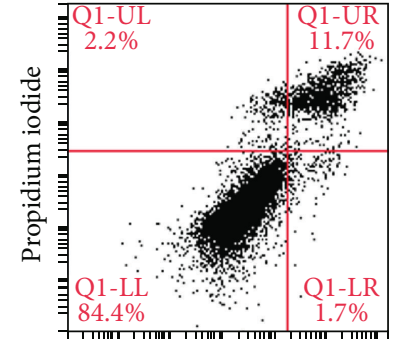

Hyperoside $0.5 \mathrm{mM} / \mathrm{L}$

Annexin-V

$48 \mathrm{~h}$

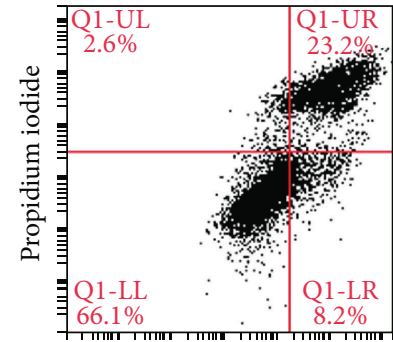

Hyperoside $2 \mathrm{mM} / \mathrm{L}$

Annexin- $\mathrm{V}$

$48 \mathrm{~h}$

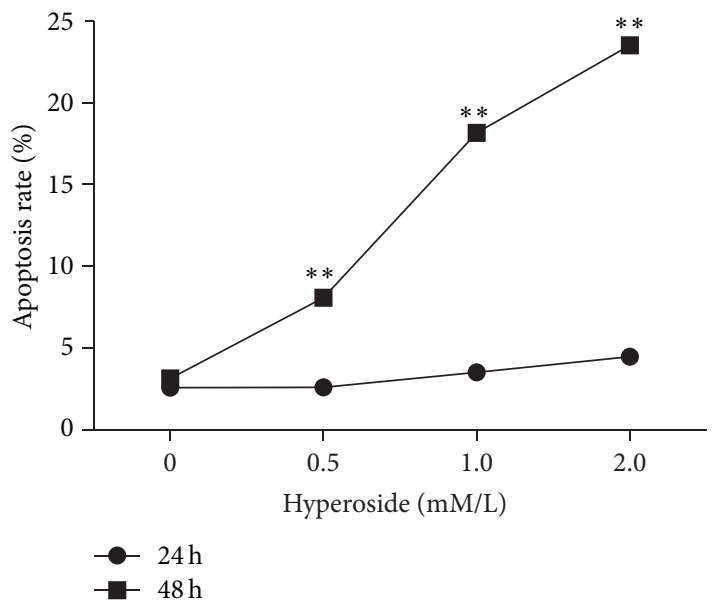

FIGURE 2: Hyperoside induced proapoptosis effect and its statistical representation of data. The apoptosis rate of Lx-2 cells was analyzed by flow cytometry (Annexin V-FITC/PI). Cells were treated with different dose of hyperoside $(0,0.5,1.0$, and $2.0 \mathrm{mM} / \mathrm{L})$ for $24 \mathrm{~h}$ and $48 \mathrm{~h}$, respectively. Results represent the mean \pm SEM from three independent experiments $\left({ }^{* *}\right.$ means compared with the control group, $P<0.001$, $n=3)$.

3.6. Hyperoside Induces HSC Apoptosis by Mediating NF$\kappa B$-Dependent Genes. The NF- $\kappa \mathrm{B}$ transcription factor complex regulates genes governing a wide range of biological functions; these genes include regulators of apoptosis and cell proliferation such as Fas, FasL, DR4, and Bcl- $X_{L}[24$, 25], and NF- $\kappa \mathrm{B}$ mediates cell death by the upregulation or downregulation of these target genes. To gain further insight into the effects of hyperoside on the regulation of NF- $\kappa \mathrm{B}$ target genes in LX-2 cells, we assayed the expression of several proapoptotic genes $(\mathrm{Bcl}-\mathrm{Xs}, \mathrm{DR} 4, \mathrm{Fas}, \mathrm{FasL})$ and antiapoptotic genes (A20, $c$-IAP1, Bcl- $\left.X_{L}, R I P 1\right)$ by real-time PCR following hyperoside treatment. As shown in Figure 5(b), we detected a dose-dependent upregulation of proapoptotic genes after $48 \mathrm{~h}$ of hyperoside treatment, with the largest increases in mRNA levels observed in DR4 and FasL. Conversely, the expression of antiapoptotic genes $B c l-X_{L}, c-I A P 1$, and Rip1 decreased with increasing doses of hyperoside.

\section{Discussion}

Recently, naturally occurring plant compounds have become attractive subjects of research into novel therapeutic strategies for liver fibrosis. In particular, dietary flavonoids such as morin [26], hesperidin [27], and silymarin [28] have 


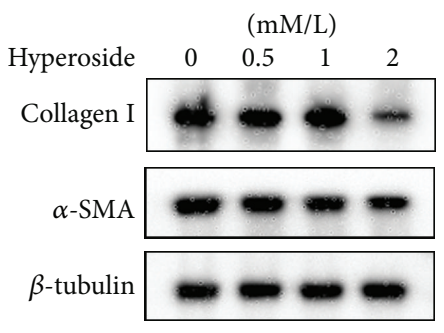

(a)
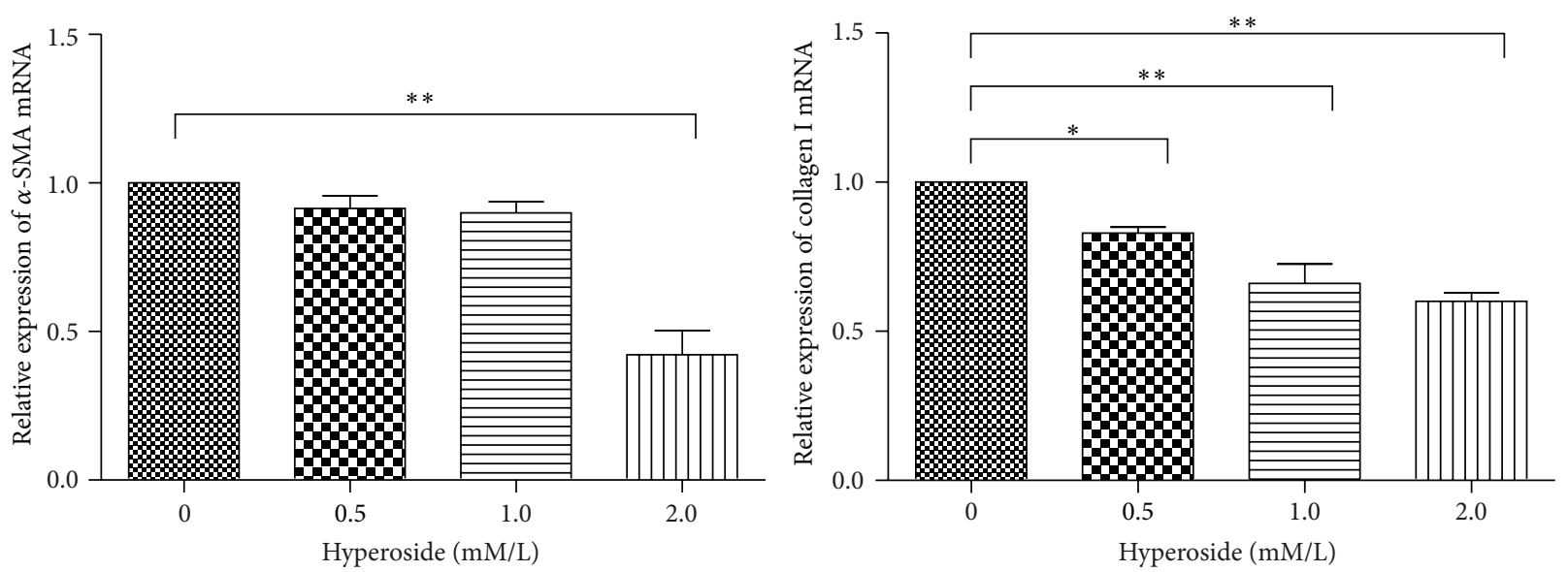

(b)

FIGURE 3: Hyperoside attenuated LX-2 activation. (a) Western blotting analysis of $\alpha$-SMA and collagen I. The relative expression of proteins was calculated according to the reference band of $\beta$-tubulin. (b) mRNA levels were quantitated by real-time PCR. The expression was analyzed by $2^{-\Delta \Delta \mathrm{CT}}$ method. 18s mRNA was used as a housekeeping gene $\left({ }^{*}\right.$ means compared with the control group, $P<0.05 ;{ }^{* *}$ means compared with the control group, $P<0.001, n=3)$.

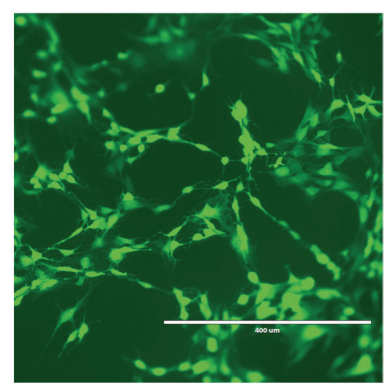

Hyperoside $0 \mathrm{mM} / \mathrm{L}$

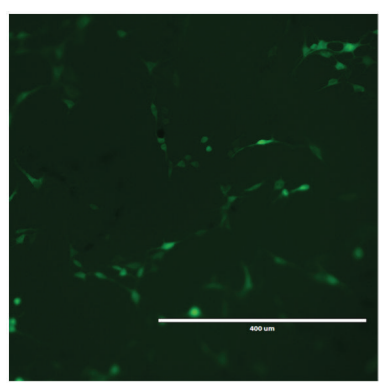

Hyperoside $1 \mathrm{mM} / \mathrm{L}$

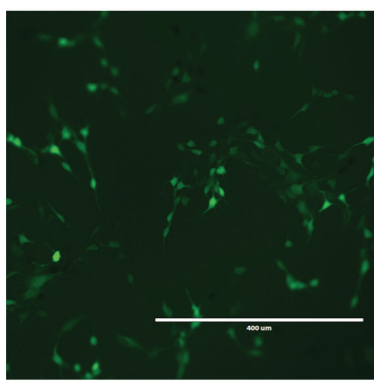

Hyperoside $0.5 \mathrm{mM} / \mathrm{L}$

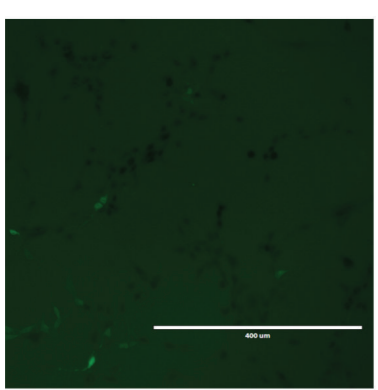

Hyperoside $2 \mathrm{mM} / \mathrm{L}$

(a)

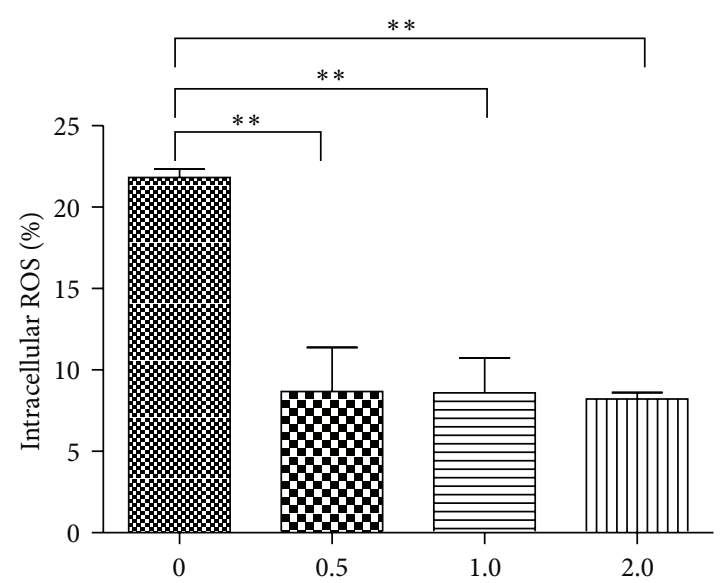

Hyperoside $(\mathrm{mM} / \mathrm{L})$

(b)

FIGURE 4: (a) LX-2 cells were treated in the absence or presence of hyperoside with different concentration for $24 \mathrm{~h}$. The cells were then stained with DCF-DA and subjected to fluorescence microscopy. (b) Intracellular ROS was detected with flow cytometry. 


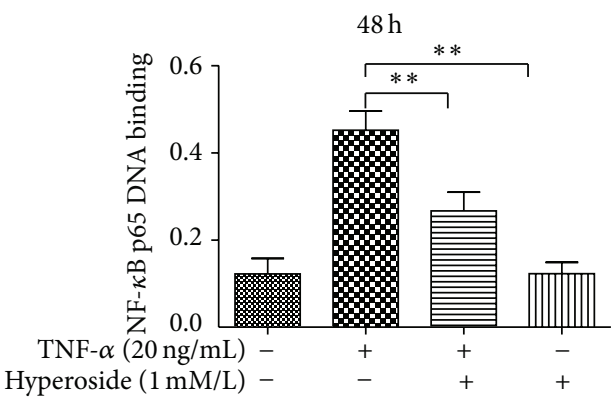

(a)
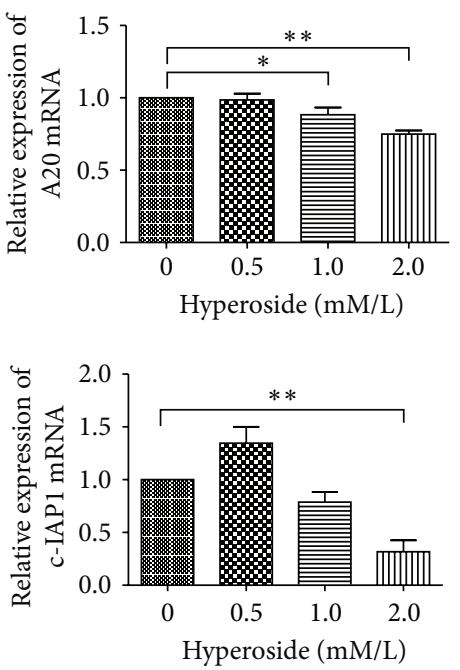
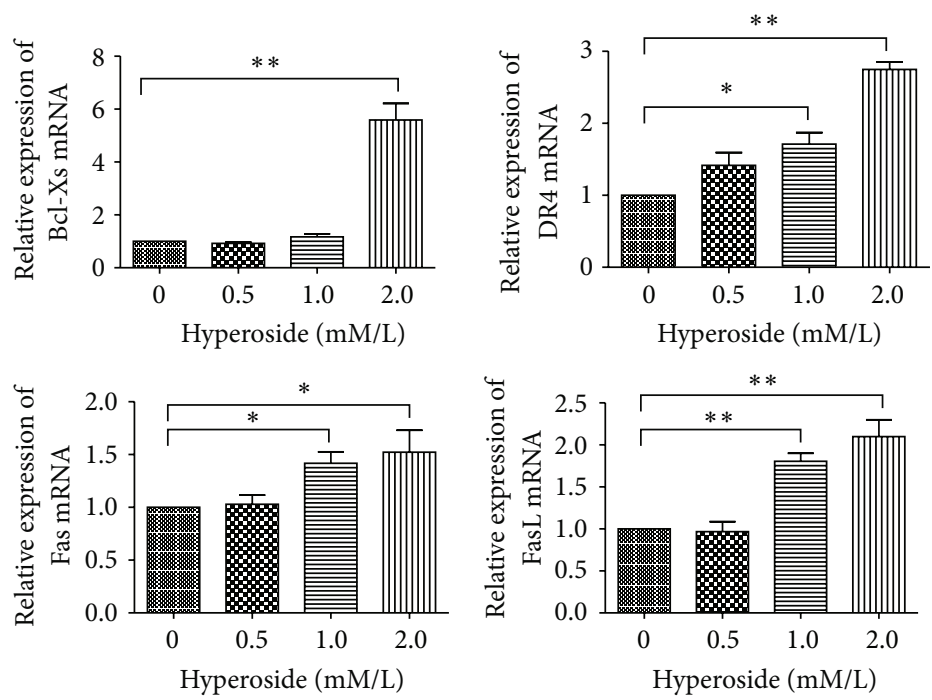

(b)
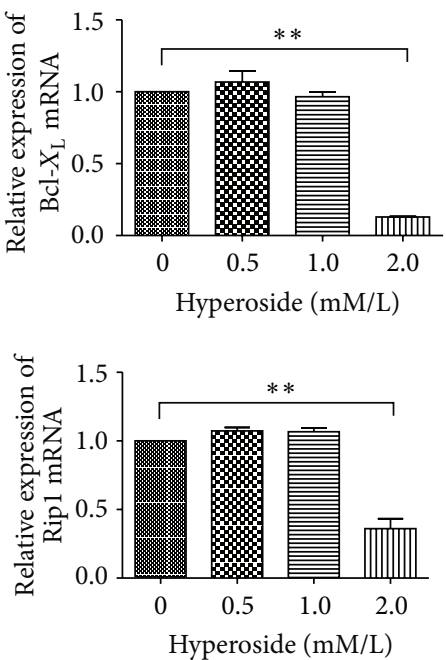

(c)

Figure 5: Hyperoside induces HSC apoptosis by blocking NF- $\kappa$ B activation and mediating NF- $\kappa$ B-dependent genes. (a) Hyperoside blocks NF- $\kappa$ B activation in Lx- 2 cells. The effect of hyperoside on NF- $\kappa$ B DNA-binding activity in LX- 2 cells was evaluated by ELISA. LX-2 cells were incubated for 48 hours in the absence or presence of TNF- $\alpha(20 \mathrm{ng} / \mathrm{mL})$ and hyperoside $(1 \mathrm{mM} / \mathrm{L})$. Nuclear protein was extracted and subjected to ELISA for measurement of NF- $\kappa$ B DNA-binding activity. (b) Relative expression of NF- $\kappa$ B mediating proapoptotic target genes. (c) Relative expression of NF- $\kappa$ B mediating antiapoptotic target genes $\left({ }^{*}\right.$ means compared with the control group, $P<0.05$; ${ }^{* *}$ means compared with the control group, $P<0.001, n=3$ ).

been reported to attenuate the process of fibrosis. Hyperoside has been shown to have pleiotropic pharmacological effects, which include antithrombotic activities [29], protective effects on cardiomyocytes [30], and anti-inflammatory activities [31]. A recent report suggested that hyperoside exhibits hepatoprotective effects against $\mathrm{CCl}_{4}$-induced liver injury and suppresses inflammation, but the mechanisms by which it protects against liver cirrhosis still need to be elucidated [32]. In the present study, we demonstrated that hyperoside induced culture-activated HSCs to undergo apoptosis due to downregulation of intercellular ROS and thereby inhibition of NF- $\kappa$ B.
NF- $\kappa \mathrm{B}$ signaling plays an active role in a number of chronic liver diseases $[10,33]$. There is evidence of NF- $\kappa \mathrm{B}$ activity in activated HSCs $[6,34]$ and the inhibition of HSC apoptosis promotes liver fibrosis [7, 11,35]. Inhibition of NF- $\kappa \mathrm{B}$ signaling is usually connected with the induction of apoptosis in activated HSCs and the resolution of experimentally induced liver fibrosis [36]. For example, gliotoxin [7] and resveratrol [37] can induce HSC apoptosis both in vitro and in vivo through the inhibition of NF- $\kappa \mathrm{B}$ signaling and altered regulation of NF- $\kappa \mathrm{B}$-dependent gene transcription [38]. Consistent with these reports, we observed that when hyperoside was administered to LX-2 cells for $48 \mathrm{~h}$, late 
apoptotic and necrotic cells (Figure 2) were increased significantly. In the early apoptosis stage, cells trigger ultimate loss of the mitochondrial membrane potential and translocation of phosphatidylserine. Early apoptotic cells can be rescued from the apoptotic program if the apoptotic stimulus is removed [39]. In our study, for early and median apoptotic cells, there is slighter change in $24 \mathrm{~h}$ than in $48 \mathrm{~h}$ perhaps for LX- 2 cells $24 \mathrm{~h}$ hyperosdie treatment is not as effective as $48 \mathrm{~h}$, which is consistent with the result of cell viability assay that for $48 \mathrm{~h} \mathrm{IC} \mathrm{IC}_{50}$ is lower than that in $24 \mathrm{~h}$. As a consequence of NF- $\kappa \mathrm{B}$ signaling inhibition, active markers for HSCs $\alpha$-SMA and type I collagen were reduced by hyperoside in LX-2 cells.

Theoretically, ROS represent a serious hazard for the cell, as not only can they oxidize macromolecules-thus damaging proteins, lipids, and DNA [40]—but they are also key secondary messengers in numerous signaling pathways including proliferation, metabolism, and apoptosis [41]. In the liver, ROS contribute to hepatic fibrosis triggered by numerous liver injuries, including alcohol abuse, HCV infection, iron overload, and chronic cholestasis [42, 43]. Importantly, several studies have found that ROS influence intracellular NF- $\kappa \mathrm{B}$ signaling [44] and stimulate collagen gene induction in HSCs, contributing to the pathogenesis of liver fibrosis [45]. Interestingly, studies have revealed the existence of a reciprocal, negative feedback loop between NF$\kappa \mathrm{B}$ and ROS [41]. Hyperoside is a quercetin-3-O-galactoside compound with a catechol group in the B-ring. Based on established structure-antioxidant activity relationships [46], we hypothesized that hyperoside would exert the suppressive capacity of intercellular ROS in HSCs. As expected, our experimental results indicate that hyperoside attenuates the generation of intracellular ROS and decreases the activation of NF- $\kappa \mathrm{B}$.

Collectively, our results suggest that the antifibrotic effects of hyperoside on cultured LX-2 cells are mediated by the inhibition of canonical NF- $\kappa \mathrm{B}$ signaling and the induction of apoptosis in activated HSCs. Hyperoside can be regarded as a potential candidate in the search for pharmacological agents to combat liver fibrosis, although the precise mechanisms involved remain to be discovered, and extensive preclinical experiments are still required. Plants possessing the hyperoside compound are abundant in China [47], and many of these are considered to be atoxic and edible according to traditional Chinese medicine. This study adds support to the notion that the development of novel medicines and healthpromoting foods based on hyperoside is a viable strategy, especially in China, and represents a valuable research goal because liver cirrhosis arising from viral hepatitis remains a serious global health issue.

\section{Competing Interests}

The authors declare that there are no competing interests regarding the publication of this paper.

\section{Authors' Contributions}

Liwen Wang and Zhiwei Yue have equal contribution.

\section{Acknowledgments}

This study was supported by National Natural Science Foundation of China (Grant nos. 81172837 and 31571832), Tianjin Innovative Research Team Grant (TD-12-5049), Tianjin Municipal Science and Technology Commission (Grant no. 13JCQNJC12200), and National Student Innovation Programme (201510069043).

\section{References}

[1] P. Angulo, D. E. Kleiner, S. Dam-Larsen et al., "Liver fibrosis, but no other histologic features, is associated with long-term outcomes of patients with nonalcoholic fatty liver disease," Gastroenterology, vol. 149, no. 2, pp. 389.e10-397.e10, 2015.

[2] V. Hernandez-Gea and S. L. Friedman, "Pathogenesis of liver fibrosis," Annual Review of Pathology: Mechanisms of Disease, vol. 6, pp. 425-456, 2011.

[3] D. Schuppan and N. H. Afdhal, "Liver cirrhosis," The Lancet, vol. 371, no. 9615, pp. 838-851, 2008.

[4] H. B. El-Serag and K. L. Rudolph, "Hepatocellular carcinoma: epidemiology and molecular carcinogenesis," Gastroenterology, vol. 132, no. 7, pp. 2557-2576, 2007.

[5] R. I. A. Rippe and D. A. A. Brenner, "From quiescence to activation: gene regulation in hepatic stellate cells," Gastroenterology, vol. 127, no. 4, pp. 1260-1262, 2004.

[6] A. Anan, E. S. Baskin-Bey, S. F. Bronk, N. W. Werneburg, V. H. Shah, and G. J. Gores, "Proteasome inhibition induces hepatic stellate cell apoptosis," Hepatology, vol. 43, no. 2, pp. 335-344, 2006.

[7] M. C. Wright, R. Issa, D. E. Smart et al., "Gliotoxin stimulates the apoptosis of human and rat hepatic stellate cells and enhances the resolution of liver fibrosis in rats," Gastroenterology, vol. 121, no. 3, pp. 685-698, 2001.

[8] E. Crosas-Molist, E. Bertran, and I. Fabregat, "Cross-talk between TGF- $\beta$ and NADPH oxidases during liver fibrosis and hepatocarcinogenesis," Current Pharmaceutical Design, vol. 21, no. 41, pp. 5964-5976, 2015.

[9] T. D. Gilmore, "Introduction to NF- $\kappa$ B: players, pathways, perspectives," Oncogene, vol. 25, no. 51, pp. 6680-6684, 2006.

[10] T. Luedde and R. F. Schwabe, "NF- $\kappa$ B in the liver-linking injury, fibrosis and hepatocellular carcinoma," Nature Reviews Gastroenterology and Hepatology, vol. 8, no. 2, pp. 108-118, 2011.

[11] F. Oakley, M. Meso, J. P. Iredale et al., "Inhibition of inhibitor of $\kappa \mathrm{b}$ kinases stimulates hepatic stellate cell apoptosis and accelerated recovery from rat liver fibrosis," Gastroenterology, vol. 128, no. 1, pp. 108-120, 2005.

[12] A. M. Elsharkawy, F. Oakley, and D. A. Mann, "The role and regulation of hepatic stellate cell apoptosis in reversal of liver fibrosis," Apoptosis, vol. 10, no. 5, pp. 927-939, 2005.

[13] D. F. Romagnolo and O. I. Selmin, "Flavonoids and cancer prevention: a review of the evidence," Journal of Nutrition in Gerontology and Geriatrics, vol. 31, no. 3, pp. 206-238, 2012.

[14] D. Sampietro, E. Quiroga, M. Sgariglia, J. Soberón, and M. A. Vattuone, "A thermostable $\alpha$-galactosidase from Lenzites elegans (Spreng.) ex Pat. MB445947: purification and properties," Antonie van Leeuwenhoek, vol. 102, no. 2, pp. 257-267, 2012. 
[15] S. Trumbeckaite, J. Bernatoniene, D. Majiene, V. Jakštas, A. Savickas, and A. Toleikis, "The effect of flavonoids on rat heart mitochondrial function," Biomedicine and Pharmacotherapy, vol. 60 , no. 5 , pp. $245-248,2006$.

[16] W. Zhou, J. Oh, W. Li, D. W. Kim, S. H. Lee, and M. K. Na, "Phytochemical studies of Korean endangered plants: a new flavone from Rhododendron brachycarpum G. Don," Bulletin of the Korean Chemical Society, vol. 34, no. 8, pp. 2535-2538, 2013.

[17] S.-K. Ku, S. Kwak, O.-J. Kwon, and J.-S. Bae, "Hyperoside inhibits high-glucose-induced vascular inflammation in vitro and in vivo," Inflammation, vol. 37, no. 5, pp. 1389-1400, 2014.

[18] L.-L. Wu, X.-B. Yang, Z.-M. Huang, H.-Z. Liu, and G.-X. Wu, "In vivo and in vitro antiviral activity of hyperoside extracted from Abelmoschus manihot (L) medik," Acta Pharmacologica Sinica, vol. 28, no. 3, pp. 404-409, 2007.

[19] L. Xu, A. Y. Hui, E. Albanis et al., "Human hepatic stellate cell lines, LX-1 and LX-2: new tools for analysis of hepatic fibrosis," Gut, vol. 54, no. 1, pp. 142-151, 2005.

[20] D. Diaz, A. Prieto, E. Reyes, H. Barcenilla, J. Monserrat, and M. Alvarez-Mon, "Flow cytometry enumeration of apoptotic cancer cells by apoptotic rate," Methods in Molecular Biology, vol. 1219, pp. 11-20, 2015.

[21] C. Zhu, Z. Lei, and Y. Luo, "Studies on antioxidative activities of methanol extract from Murraya paniculata," Food Science and Human Wellness, vol. 4, no. 3, pp. 108-114, 2015.

[22] S. De Minicis and D. A. Brenner, "NOX in liver fibrosis," Archives of Biochemistry and Biophysics, vol. 462, no. 2, pp. 266272, 2007.

[23] Y.-H. Paik, K. Iwaisako, E. Seki et al., “The nicotinamide adenine dinucleotide phosphate oxidase (NOX) homologues NOX1 and NOX2/gp91phox mediate hepatic fibrosis in mice," Hepatology, vol. 53, no. 5, pp. 1730-1741, 2011.

[24] J. Kucharczak, M. J. Simmons, Y. Fan, and C. Gélinas, “To be, or not to be: NF- $\kappa \mathrm{B}$ is the answer-role of Rel/NF- $\kappa \mathrm{B}$ in the regulation of apoptosis," Oncogene, vol. 22, no. 56, pp. 89618982, 2003.

[25] S. K. Radhakrishnan and S. Kamalakaran, "Pro-apoptotic role of NF- $\kappa$ B: implications for cancer therapy," Biochimica et Biophysica Acta-Reviews on Cancer, vol. 1766, no. 1, pp. 53-62, 2006.

[26] P. MadanKumar, P. NaveenKumar, S. Manikandan, H. Devaraj, and S. NiranjaliDevaraj, "Morin ameliorates chemically induced liver fibrosis in vivo and inhibits stellate cell proliferation in vitro by suppressing Wnt/ $\beta$-catenin signaling," Toxicology and Applied Pharmacology, vol. 277, no. 2, pp. 210-220, 2014.

[27] S. M. Elshazly and A. A. A. Mahmoud, "Antifibrotic activity of hesperidin against dimethylnitrosamine-induced liver fibrosis in rats," Naunyn-Schmiedeberg's Archives of Pharmacology, vol. 387, no. 6, pp. 559-567, 2014.

[28] S. Clichici, D. Olteanu, A.-L. Nagy, A. Oros, A. Filip, and P. A. Mircea, "Silymarin inhibits the progression of fibrosis in the early stages of liver injury in CCl4-treated rats," Journal of Medicinal Food, vol. 18, no. 3, pp. 290-298, 2015.

[29] S.-K. Ku, T. H. Kim, S. Lee, S. M. Kim, and J.-S. Bae, "Antithrombotic and profibrinolytic activities of isorhamnetin3-O-galactoside and hyperoside," Food and Chemical Toxicology, vol. 53, pp. 197-204, 2013.

[30] Z.-L. Li, J. Hu, Y.-L. Li et al., "The effect of hyperoside on the functional recovery of the ischemic/reperfused isolated rat heart: potential involvement of the extracellular signalregulated kinase 1/2 signaling pathway," Free Radical Biology and Medicine, vol. 57, pp. 132-140, 2013.

[31] S. Lee, H. J. Sang, S. L. Yeon et al., "Antiinflammatory activity of hyperin from Acanthopanax chiisanensis roots," Archives of Pharmacal Research, vol. 27, no. 6, pp. 628-632, 2004.

[32] J.-H. Choi, D.-W. Kim, N. Yun et al., "Protective effects of hyperoside against carbon tetrachloride-induced liver damage in mice," Journal of Natural Products, vol. 74, no. 5, pp. 10551060, 2011.

[33] V. Sivaramakrishnan and S. Niranjali Devaraj, "Morin regulates the expression of NF- $\kappa \mathrm{B}-\mathrm{p} 65, \mathrm{COX}-2$ and matrix metalloproteinases in diethylnitrosamine induced rat hepatocellular carcinoma," Chemico-Biological Interactions, vol. 180, no. 3, pp. 353-359, 2009.

[34] A. Lang, R. Schoonhoven, S. Tuvia, D. A. Brenner, and R. A. Rippe, "Nuclear factor $\kappa \mathrm{B}$ in proliferation, activation, and apoptosis in rat hepatic stellate cells," Journal of Hepatology, vol. 33, no. 1, pp. 49-58, 2000.

[35] A. M. Elsharkawy, M. C. Wright, R. T. Hay et al., "Persistent activation of nuclear factor- $\kappa \mathrm{B}$ in cultured rat hepatic stellate cells involves the induction of potentially novel rel-like factors and prolonged changes in the expression of $\mathrm{I} \kappa \mathrm{B}$ family proteins," Hepatology, vol. 30, no. 3, pp. 761-769, 1999.

[36] S. L. Friedman, "Evolving challenges in hepatic fibrosis," Nature Reviews Gastroenterology and Hepatology, vol. 7, no. 8, pp. 425436, 2010.

[37] E. Chávez, K. Reyes-Gordillo, J. Segovia et al., "Resveratrol prevents fibrosis, NF- $\kappa$ B activation and TGF- $\beta$ increases induced by chronic $\mathrm{CCl}_{4}$ treatment in rats," Journal of Applied Toxicology, vol. 28, no. 1, pp. 35-43, 2008.

[38] F. Habens, N. Srinivasan, F. Oakley, D. A. Mann, A. Ganesan, and G. Packham, "Novel sulfasalazine analogues with enhanced NF-kB inhibitory and apoptosis promoting activity," Apoptosis, vol. 10, no. 3, pp. 481-491, 2005.

[39] S. Elmore, "Apoptosis: a review of programmed cell death," Toxicologic Pathology, vol. 35, no. 4, pp. 495-516, 2007.

[40] J. F. Curtin, M. Donovan, and T. G. Cotter, "Regulation and measurement of oxidative stress in apoptosis," Journal of Immunological Methods, vol. 265, no. 1-2, pp. 49-72, 2002.

[41] C. Bubici, S. Papa, K. Dean, and G. Franzoso, "Mutual crosstalk between reactive oxygen species and nuclear factor-kappa B: molecular basis and biological significance," Oncogene, vol. 25, no. 51, pp. 6731-6748, 2006.

[42] M. Parola and G. Robino, "Oxidative stress-related molecules and liver fibrosis," Journal of Hepatology, vol. 35, no. 2, pp. 297306, 2001.

[43] G. Poli and M. Parola, "Oxidative damage and fibrogenesis," Free Radical Biology and Medicine, vol. 22, no. 1-2, pp. 287-305, 1997.

[44] A. Szuster-Ciesielska, K. Plewka, J. Daniluk, and M. KandeferSzerszeń, "Zinc supplementation attenuates ethanol- and acetaldehyde-induced liver stellate cell activation by inhibiting reactive oxygen species (ROS) production and by influencing intracellular signaling," Biochemical Pharmacology, vol. 78, no. 3, pp. 301-314, 2009.

[45] N. Nieto, P. Greenwel, S. L. Friedman, F. Zhang, A. J. Dannenberg, and A. I. Cederbaum, "Ethanol and arachidonic acid increase $\alpha 2(\mathrm{I})$ collagen expression in rat hepatic stellate 
cells overexpressing cytochrome P450 2E1. Role of $\mathrm{H}_{2} \mathrm{O}_{2}$ and cyclooxygenase-2," The Journal of Biological Chemistry, vol. 275, no. 26, pp. 20136-20145, 2000.

[46] K. E. Heim, A. R. Tagliaferro, and D. J. Bobilya, "Flavonoid antioxidants: chemistry, metabolism and structure-activity relationships," Journal of Nutritional Biochemistry, vol. 13, no. 10, pp. 572-584, 2002.

[47] S. Donnapee, J. Li, X. Yang et al., "Cuscuta chinensis Lam.: a systematic review on ethnopharmacology, phytochemistry and pharmacology of an important traditional herbal medicine," Journal of Ethnopharmacology, vol. 157, pp. 292-308, 2014. 

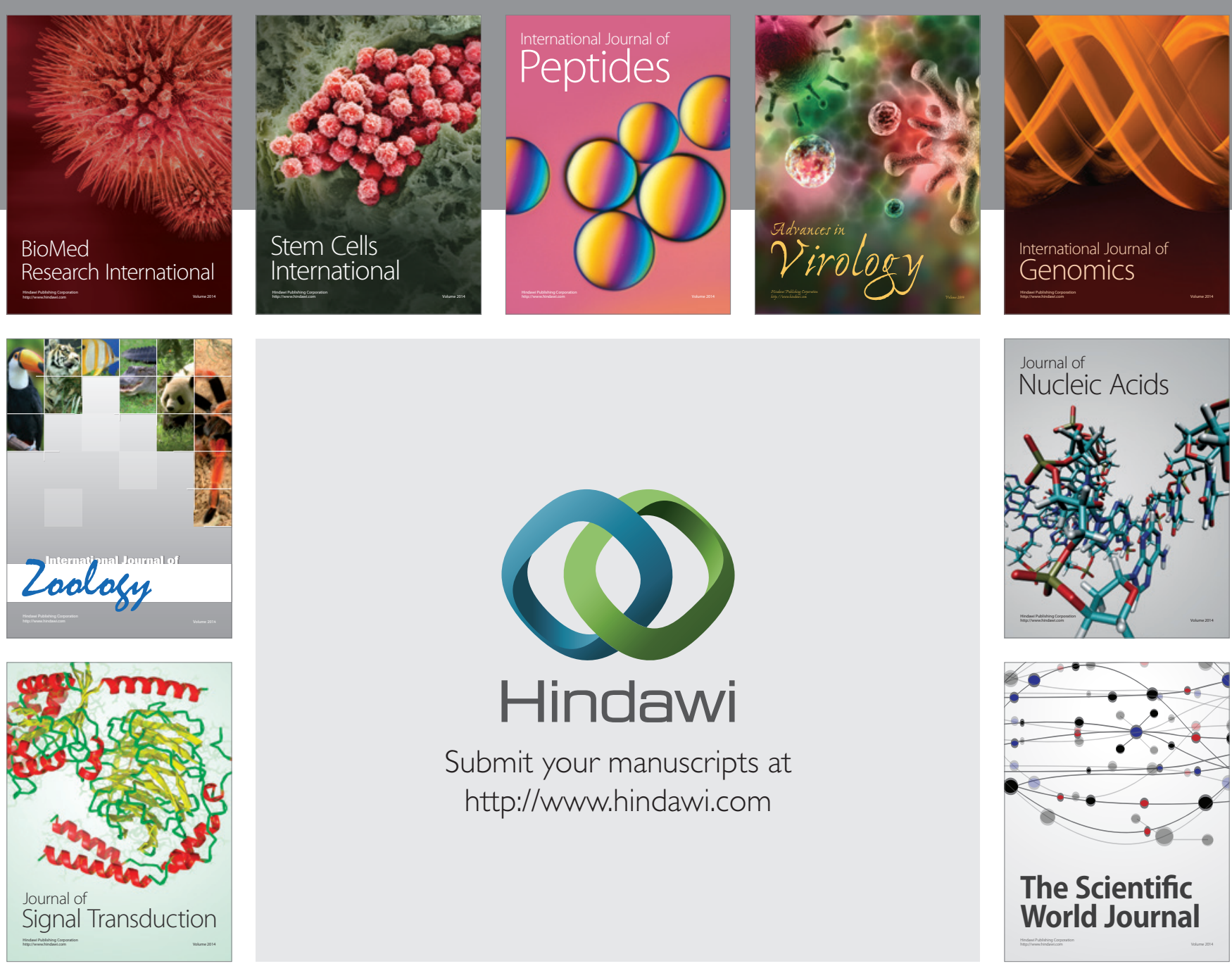

Submit your manuscripts at

http://www.hindawi.com
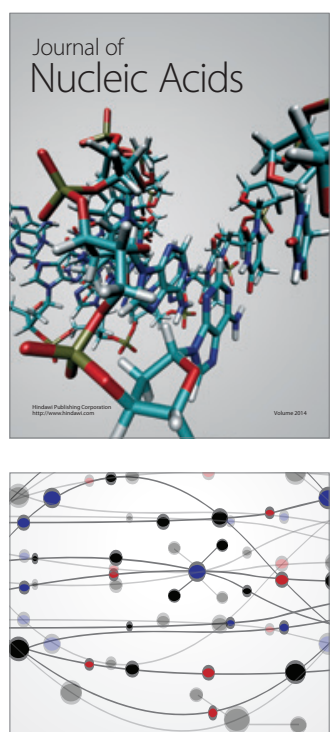

The Scientific World Journal
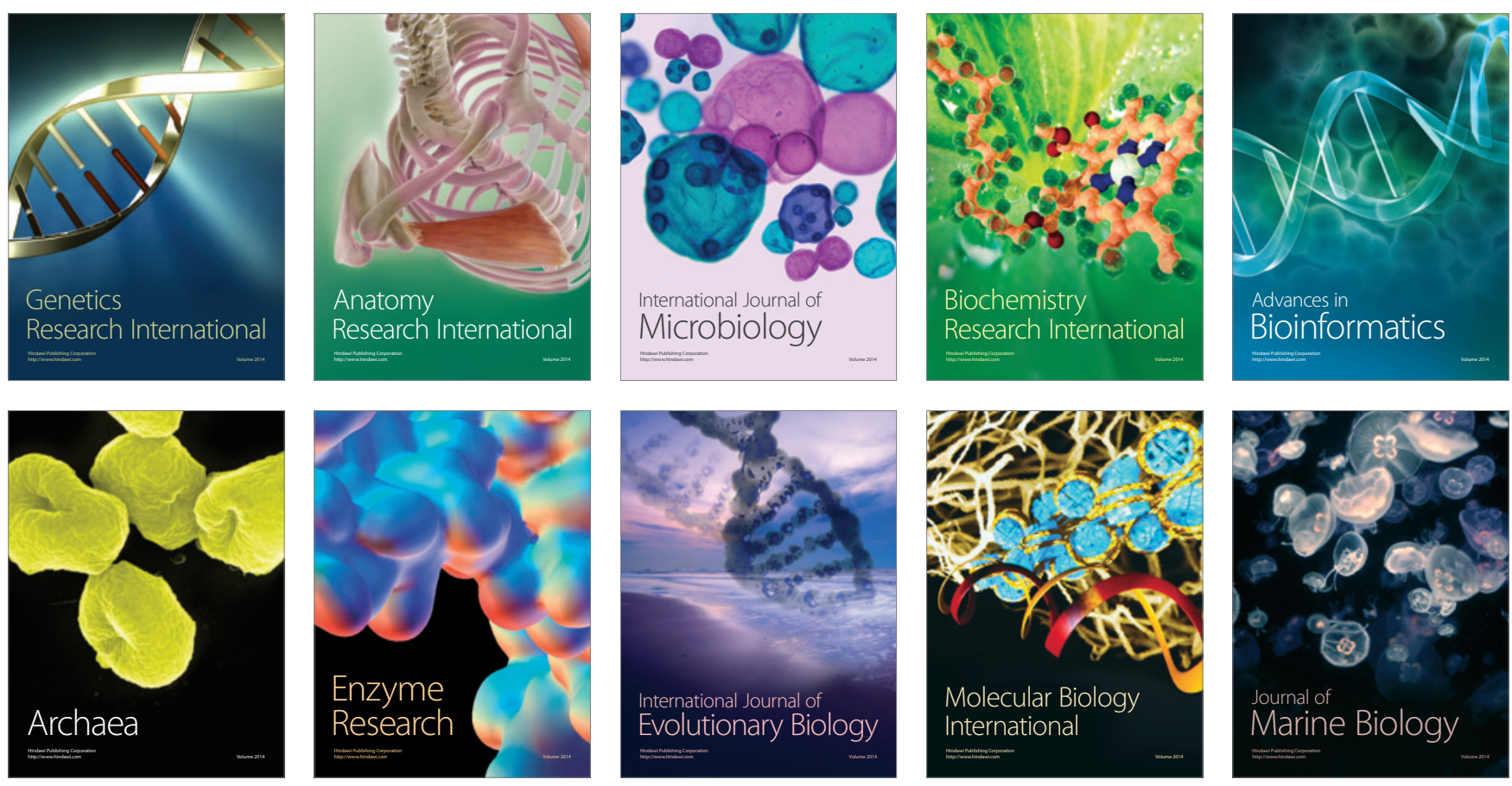